\title{
Designing Authentic Learning Activities to Train Pre- Service Teachers About Teaching Online
}

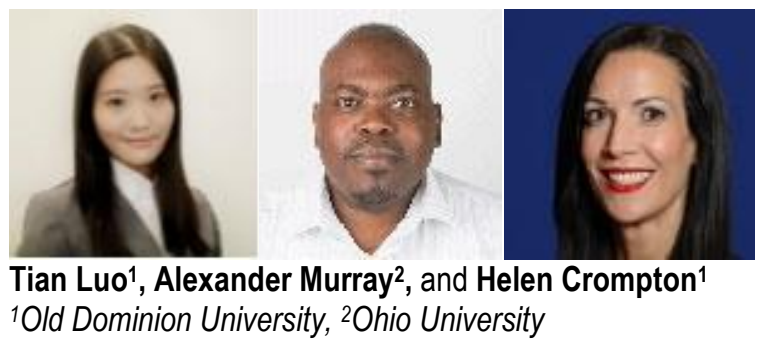

\begin{abstract}
Online learning is increasingly being used in K-12 learning environments. A concomitant trend is found towards learning becoming authentic as students learn with tasks that are connected to realworld occupations. In this study, 48 pre-service teachers use an online environment to engage in authentic practice as they developed online learning experiences for their future students. Using a design-based research methodology, the researchers were involved in planning, designing, implementing, and evaluating the higher education class across two macro cycles. An authentic learning framework was utilized in the development of the class. Findings explicate the design of the course and how it aligned to the authentic learning framework. It appears that web-based tools were beneficial as the pre-service teachers designed their own K-12 online classes. Findings show that the pre-service teachers' comfort increased when using the using online web building applications in the authentic environment. Furthermore, a high level of engagement in reflective and collaborative learning was uncovered during the activities. This research acts as a springboard for educators who are interested in designing online higher education courses incorporating authentic learning experiences.
\end{abstract}

Keywords: authentic learning, Web 2.0, teacher education, online teaching

\section{Introduction}

Teacher training programs have consistently been challenged by their incompetency in preparing preservice teachers for the ever-changing reality of modern classrooms (Blackwell, Futrell, \& Imig, 2003; Cusworth \& Whiting, 1994). Traditional methods of teaching, such as lecturing in large-lecture halls, often fail to keep students' attention and engagement (El-Ghareeb \& Riad, 2011). It appears that a dichotomy exists between how pre-service teachers are prepared to teach in classrooms and what teaching is like in the real world. Thus, pre-service teachers may be trained to answer test questions, but find it difficult to solve real problems when teaching in the classroom (Herrington \& Oliver, 2000; Gulikers, Bastiaens, \& Kirschner, 2004). To best prepare pre-service teachers for real world problem 
solving and application, authentic learning that uses a situated learning approach has been deemed an effective method (Snape \& Fox-Turnbull, 2013). As students gain opportunities to learn through a contextualized approach, there has also been a concomitant positive trend towards students taking advantage of online learning.

Online learning is the action of delivering course materials and instruction to learners by using Internet technology (Demiray, 2011). Online learning has pervaded both formal and informal K-12 learning. The International Association of K-12 Online Learning reported that in 2010 there were $1,816,400$ students enrolled in online courses and this number does not include 200,000 students attending full-time online schools (International Association for K-12 Online Learning [iNACOL], 2013). The association note that in 2013-2014 there were 310,000 students attending full-time online schools and that K-12 online learning is growing at an estimated annual pace of $30 \%$ annually (iNACOL, 2013). However, research indicates that many teacher training programs still use traditional methods (Kennedy \& Archambault, 2012a; Kennedy \& Archambault, 2012b). The reality that younger generations' lives are daily enhanced by Internet technologies and the increase in the number of students enrolling in online courses yield a need for alternative and more effective teaching methods and tools to be used (Liu \& Cavanaugh, 2011).

In teacher education programs, online instruction has emerged as an effective way to prepare preservice teachers for future teaching in online environments (Archambault, Debruler, \& Freidhoff, 2014). Researchers stressed the importance of understanding the alternative online teaching methods as necessities to achieve authentic learning and better prepare pre-service teachers in online environments (Archambault, Debruler, \& Freidhoff, 2014; Bjekic, Krneta \& Milosevic, 2010; Latham \& Carr, 2012b). To better understand authentic learning in online environments, the purpose of this study was to elucidate a design process for creating authentic learning activities for pre-service teachers in an online environment. This study includes an examination of pre-service teachers' perceptions of their online learning experiences and the technologies used. The findings of the study also reveal pedagogical implications about how to design and facilitate authentic learning for teacher education subjects in online environments.

\section{Theoretical Frameworks for Designing Authentic Learning}

\section{The Notion of Authenticity}

The notion of authenticity in education has been extensively discussed and analyzed through empirical and theoretical works. Researchers (viz., Latham, \& Carr, 2012a,Slavkin, 2004; Turnbull, 2002) postulated that its earliest theoretical strings were derived from the term authentic assessments with regards to constructivist and situated learning. Authenticity is a students' perception that tasks are connect to their lives (Behizadeh \& Fink 2015). It is associated with authentic learning outcomes that involve the evaluation of constructivist learning, disciplined enquiry, higher order thinking and problem solving (Latham \& Carr, 2012b).

Both social constructivist learning and situated learning theories stress the social and physical contexts in which learning occurs. These theories hold that learning resides in the learners' social relationships which are unintentionally situated within the authentic activity, context, and culture (Amory, 2014; Lave \& Wenger, 1991). To have a full grasp of concepts, learners must apply those 
concepts in authentic social and physical environments through participating in communities of practice (Amory, 2014; Brown, Collins, \& Duguid, 1989; Lave \& Wenger, 1991). The process of situating learning in a certain context is necessary as the process is modelled and transferred to other activities in which meanings are negotiated and therefore constructed by learners. The social and situated component of learning becomes a critical element for learning to occur.

\section{A Framework for Authentic Learning}

With growing interest in designing authentic learning environments, multiple frameworks have developed to understand authentic learning (viz., Newmann \& Wehlage, 1993; Slavkin, 2004). Drawing from researchers' different perspectives and contexts, the conceptualization of authentic learning may vary to some extent (Kreber, Klampfleitner, McCune, Bayne, \& Knottenbelt, 2007). For example, Newmann and Wehlage (1993) conceptualized five components of authentic learning from pedagogy and instruction perspectives. They contend that authentic learning entails (a) focusing on higher-order thinking as opposed to rote memorization of factual information, (b) involvement in deeper knowledge construction including problem-solving and understanding of complex meaning, (c) connectedness to the larger real-world social context, (d) engagement in substantive conversation, such as discussion and sharing of ideas and dialogue, and (e) inclusion of social support for all students to achieve high expectations.

In Slavkin's (2004) book, educators provided six requirements to achieve authentic learning: (a) teachers must be able to help students accurately review experiences, (b) skills may be difficult to apply to new settings, (c) authentic pedagogy needs complex and authentic tasks, (d) responsibility for learning is shared between teacher and student, (e) there are multiple ways to look at material, and (f) both teacher and student must be involved in ensuring learning occurs and information is applied practically (p. 9).

In reviewing several frameworks of authentic learning, a checklist of 10 characteristics of authentic activities developed by Herrington, Oliver, and Reeves (2003) was selected for this study. Their framework, as adopted, is a holistic and detailed framework to understand what authentic learning means and presents a checklist of guidelines for designing authentic learning activities (Hossainy, Zare, Hormozi, Shaghaghi, \& Kaveh, 2012; Teräs, Teräs, \& Herrington, 2012). The 10 characteristics described in the framework are:

1. Authentic activities have real-world relevance

2. Authentic activities are ill-defined, requiring students to define the tasks and sub-tasks needed to complete the activity.

3. Authentic activities comprise complex tasks to be investigated by students over a sustained period of time.

4. Authentic activities provide the opportunity for students to examine the task from different perspectives, using a variety of resources.

5. Authentic activities provide the opportunity to collaborate.

6. Authentic activities provide the opportunity to reflect. 
7. Authentic activities can be integrated and applied across different subject areas and lead beyond domain-specific outcomes.

8. Authentic activities are seamlessly integrated with assessment.

9. Authentic activities create polished products valuable in their own right rather than as preparation for something else.

10. Authentic activities allow competing solutions and diversity of outcome. (Herrington et al., 2003, p. 61)

\section{Study Purpose}

In this study, the instructional design framework for authentic learning (Herrington, et al., 2003) was used to develop an online course for pre-service teachers. The authentic activity designed for this class was to have the pre-service teachers design an online course for their own students that also incorporated authentic activities. Furthermore, as authentic activities are motivating to learners (Martens, Gulikers, \& Bastiaens, 2004) it was anticipated that these activities would have the preservice teachers motivated to learn in the class. The three research questions that guided this study are:

1. How was Herrington et al.'s (2003) framework used to integrate authentic activities into the design of an online course for pre-service teachers?

2. What were the pre-service teachers' perceptions of the online authentic learning experiences?

3. How did technology facilitate the authentic online learning process?

\section{Methods}

\section{Design-Based Research}

In this study, we followed a design-based research methodology (Wang \& Hannafin, 2005), which is a pragmatic research approach that involves the planning, designing, implementation, and evaluating of a teaching intervention aiming at delivering outcomes that are constructed in real-world contexts (Middleton, Gorard, Taylor, \& Bannan-Ritland, 2008; Wang \& Hannafin, 2005). This design-based research approach is of critical value to improving curriculum development, renovating instructional strategies, and reassessing learning. Through incorporating the authentic learning activities as a teaching intervention, the aim was to improve course design. This design-based research methodology involves constant reflection and revision. This study involved two macro cycles.

\section{Participants}

A total of 48 undergraduate pre-service teachers took part in this study. The first macro cycle had 22 students and the second macro cycle had 26 students. The participants were all enrolled in a teacher education program at a large Midwestern university in the United States. Since the two cycles took place in the same course of a difference session, general characteristics of participants in each session were comparable in terms of age, grade level, and major of study. There were 28 males and 20 females 
of ages 18 to 22 years. They were younger generation college students born in the 1990s. These students are considered Millennials who are relatively technology-savvy and have many areas of their lives connected to the online world (Florida, Kaimal, Oblinger, \& Blessing, 2003).

According to data from the pre-survey, participants in this study were self-reported to have a medium level of technological capability. Approximately half of the participants were comfortable with using web technologies in their learning. The responses showed that 14 of 48 participants were familiar with some web design programs, such as Google Sites, Front Page, and Weebly. More than half of the participants (27 of 48) have used some forms of textual, graphic, and video tools to create content for the web. A majority of them (45 of 48) recognized some benefits of online learning in current K-12 education. Participants believed that online learning could be effective as a supplement to traditional classroom learning in K-12, but they also pointed out that it should not be a completely replacement for classroom education.

Table 1

Participants' Prior Experience of Using Online Applications

\begin{tabular}{lllllll}
\hline Items & $\begin{array}{l}\text { Mean } \\
\text { (cycle1) }\end{array}$ & $\begin{array}{l}\text { SD } \\
\text { (cycle1) }\end{array}$ & $\begin{array}{l}\text { Mean } \\
\text { (cycle2) }\end{array}$ & $\begin{array}{l}\text { SD } \\
\text { (cycle2) }\end{array}$ & $\begin{array}{l}\text { Mean } \\
\text { (total) }\end{array}$ & $\begin{array}{l}\text { SD } \\
\text { (total) }\end{array}$ \\
\hline $\begin{array}{l}\text { 1. What is your comfort } \\
\text { level in using web-based } \\
\text { technology? }\end{array}$ & 2.5 & .95 & 2.5 & .95 & 2.5 & .95 \\
$\begin{array}{l}\text { 2. How often do you } \\
\text { engage in learning a new } \\
\text { online application? }\end{array}$ & 3.6 & .94 & 3.04 & 1.22 & 3.28 & 1.13 \\
$\begin{array}{l}\text { 3. How familiar are you } \\
\text { with using free and/or } \\
\text { open source web building } \\
\text { applications? }\end{array}$ & 3.65 & 1.18 & 4.04 & 1.19 & 3.87 & 1.19 \\
\hline
\end{tabular}

$1=$ very comfortable/very often/very familiar, $5=$ Not comfortable/Not often/Not familiar

\section{Instructional Context}

The undergraduate course in which the five instructional activities were implemented for a collegelevel hybrid course designed for pre-service teachers seeking licensure to teach in K-12. There were two sessions of the same course involved in this study. The major purpose of this course was to acquaint pre-service teachers with technology applications commonly found in educational settings. Each week the pre-service teachers were to use one technology application taught that week to create an instructional artefact. The class met three times face-to-face throughout a 15-week semester and the remaining course work was completed online.

\section{Procedures}

The study took place in two sessions of the same course taught by two different instructors in Spring 2013. The first instructor implemented the instructional activities in the first half of the semester, while the second instructor implemented those activities with modifications suggested from the first instructor in the second half of the semester. This study was made up of two macro cycles. The first 
macro cycle was in the first half of the semester and the second macro cycle was in the last half of the semester. Each macro cycle had shorter mini cycles that were ongoing. In other words, each teaching episode (each weekly class) had changes that were implemented immediately after each episode so the students benefited immediately from those changes.

At the beginning of the first macrocycle, a standardized pre-survey was used to gather information on the pre-service teacher's prior experience and perceptions of online teaching. This was conducted to better understand the learners' needs and characteristics prior to the start of class to support in the design of the authentic learning activities. To introduce the pre-service teachers to the authentic learning task, they were told that they had a student in class that was unable to attend the face-to-face class for one month due to a medical condition. The pre-service teachers were told to use Weebly, a web-based drag-and-drop website builder, to build a month-long online course for that student. Learning activities had to include four weeks of instruction supporting either math, science, English, recreation, and/or computer literacy activities. The learning activities should be enhanced by various technical web applications.

Participants were given two weeks to learn Weebly using web-based tutorials and videos, then they created the online course over a period of three weeks. Upon completion of the website, participants were instructed to review two peers' websites and use a screen-capturing technology to provide comments to other participants. Finally, the pre-service teachers wrote a blog and responded to a post-survey about their experiences and opinions about the class they had taken. Students were given prompts to reflect on the authentic activities in the blogging platform. The second macrocycle followed the same structure of activity implementation, with pre- and post-class surveys being distributed before and after the authentic learning activities. Due to the voluntary nature of data collection, we only received 38 post-class survey responses in total.

\section{Data Collection and Analysis}

Data were collected from a pre-class survey, a post-class survey, and student blogs. These data were collected and analyse throughout the two macro cycles. The pre-class survey aimed to investigate participants' prior experience and perception of online teaching as well as technology integration. The survey entailed three Likert-scale questions asking to collect data on the participants' comfort level, familiarity, and frequency of using web-based technology on a scale of 1 to 5 , ranging from $1=$ high level of usage to $5=$ low level of usage. The post-class survey had two parts. The first part consisted of five open-ended questions asking participants their perceptions on their learning experiences with a focus on whether they acknowledged the benefits of different elements in the authentic learning design and the possibilities of online teaching. Three Likert-scale questions were used to discover participants' overall perception of their online learning experience and their prospective incorporation of content. The second section of the survey focused on the use of technology, especially in the peer review activity. Open-ended questions were also asked to provide more interpretive data to the quantitative ratings.

Two of the researchers coded using 10 a priori codes (Stemler, 2001) developed by Harrington et al. (2003) to investigate the participant responses and then met to discuss inter-rater consistency. Initial discrepancies were discussed until consensus was achieved. Quantitative data was measured by calculating the means and standard deviations of participant ratings on their perception of each 
activity in the survey. The after-class blog posts were analysed to further identify the perceived benefits and challenges of incorporating authentic online learning activities.

\section{Findings}

The purpose of this study was to answer the three research questions and the findings are organized accordingly. As a reminder to the reader, the findings of design-based research focus on the design of the learning activities that the pre-service teachers engaged in. Therefore, the findings, especially for research question one describe the learning activities, any changes that need to be made to the instructional design, and how effective those approaches were in meeting the learning objectives.

\section{RQ 1: How Did the Authentic Learning Framework Integrate Into the Instructional Design of Learning Tasks?}

As changes were made to the instructional design in the macro cycles, RQ 1 show the changes that were made at the completion of macro cycle 2 to better integrate with Herrington et al.'s authentic learning characteristics. Herrington et al.'s (2003) authentic learning characteristics advanced a practicable framework for the instructional design and guided development of several learning tasks of real-world relevance that would add to participant's professional experience. All participants used Weebly to construct their own authentic learning context, which was the online course within their specified area of K-12 instruction. The course was designed to have the instructors encourage the preservice teachers to look beyond traditional pedagogic methods of teaching and curriculum development and more toward ideas for leveraging the web to supplement classroom instruction. A sample of the final project tasks and how they align to the authentic learning characteristics are articulated below:

Authentic activities have real-world relevance. The pre-service teachers developed an online course for a student who did not have access to face-to-face classroom instruction due to illness. This is one real-world reason that teachers may have to provide to their future students. From the pre-service teacher responses, it appears that they understood that although they may not wish to apply for online teaching positions, that even in traditional face-to-face classrooms they may need to have this skill to do this for some students in their future classes. From surveys it also appears that the pre-service teachers were highly motivated to engage in these tasks as they saw the real-world benefit to their future careers.

Authentic activities are ill-defined, requiring participants to define the tasks and sub-tasks needed to complete the activity. From the blog posts and survey it appears that allowing the participants to be flexible in the creation of both learning environment and instructional content is a reflection of the authentic learning characteristics defined by Herrington et al. (2003). Given that the project scenario lends responsibility to the participants to assume the role of creative educator providing an online learning environment, it was necessary to give the pre-service teachers full encouragement to move beyond individual specializations and contentment, thus exposing them to a new world of digital possibilities.

Authentic activities are comprised of complex tasks to be investigated by participants over a sustained period of time. Over the period of five weeks, project participants were responsible for adding content and revising educational content to fit within their online learning sites. The first week involved learning Weebly and researching accessible file formats that 
could either be linked or uploaded as stand-alone items. Another week included themed lesson plans such as American History, at which time participants were required to structure an online lesson plan using a selection of fact-based digital slides or instructional videos that focused on a historical event. Each lesson would be followed by an assessment delivered through the online learning site. The participants' blog responses and open-ended comments showed the pre-service teachers understanding of this process building over time. For example, one participant commented, "My concerns before the project was how much time it was going to take, and making great lesson plans for my student. After the project I was just relieved to see that my hard work paid off and I believe I created a really good site."

Authentic activities provide the opportunity for participants to examine the task from different perspectives, using a variety of resources. The researchers allowed plenty of opportunities for participants to examine the task and provided a wide variety of resources to guide the pre-service teachers towards success. Oftentimes educators may have to explore a variety of tools to assure that they fit within the context of the lesson or learning environment. The preservice teachers were also provided with multiple types of modelling, including worksheets, guidelines, exemplar websites, and demonstrations of how to work with specific types of technologies through video conferencing and online tutorials. Participants reported in the blogs and the survey responses that approaching the task from different angles and attaining a wide variety of resources prepared them better for future teaching practice. As one participant noted, "In preparing this eLearning site it really made me feel like a teacher. It was great practice for something I could very well be doing in the future."

Authentic activities provide the opportunity to collaborate. Throughout the project sequence, the pre-service teacher participants were given several opportunities to collaborate in groups to discuss each other's website. First, they were grouped into different units of three to five people with similar interest and disciplinary background. Later, participants were encouraged to use varying technologies to facilitate the collaboration process, such as wikis, Twitter, and blogs hosted by the instructors. From the surveys, a great number of participants revealed that they enjoyed the peer assessment activity where they were allowed to provide rich feedback and insights to each other and help their peers to improve their websites. When providing feedback for one another, it also offered an opportunity for them to see their own work from a different lens. For example, one student commented, "the [peers'] comments allowed me to see some constructive criticism about my website from someone else's perspective." The pre-service teachers also reported that they adopted the peer feedback and used it to make enhancements to their own sites accordingly, prior to submitting their final version.

Authentic activities provide the opportunity to reflect. Participants were given multiple opportunities to reflect upon what was learned and articulate their rationale for content decisions. Throughout the process of creating the online learning site, participants were required to update their blogs on a weekly basis with information pertaining to the course or project in general. A hosted wiki page was created so that participants could add their site link for open review by both class members and the course instructor. In doing this, participants benefited from direct comments from the instructor and even gained insights from viewing their classmates' sites. Specific problems and issues of the website were easily identified, brought about, and later addressed subsequently through this periodic review afforded by blogs and wikis. For example, some pre-service teachers 
pointed out in the surveys that the superiority of using hyperlinked buttons instead of posting an extended list of pure text-based links. They also commented that the blogging activity provided them ample opportunities to think more in-depth of all the activities as a whole and the comments they received from peer review activity helped them perceive their own work from a different perspective.

Authentic activities can be integrated and applied across different subject areas and lead beyond domain-specific outcomes. The assignment was designed to promote learning outcomes from varying disciplines and domains and to enhance pre-service teachers' engagement through involving them in diverse roles and practicing different expertise. The pre-service teachers were also required to submit a project description, which enunciates the division of work according to each group member's specialization and expertise. The peer review activity again switched participant' roles from a collaborator to a reviewer, enabling them to use their own knowledge and expertise to provide peer feedback for one another. As one participant elaborated, "I think that the peer review comments helped me improve my online learning site. I didn't really think about some of the things that they mentioned beforehand so it was nice to see what others thought from their point of view. Also when making a website you don't really see things as confusing since you created it, but hearing other people's opinions really helps."

Authentic activities are seamlessly integrated with assessment. Both formative and summative assessments were integrated into multiple authentic activities in the online learning assignment. Throughout the website design and development process, instructors provided periodical check-ups and maintained continuous monitoring of the pre-service teachers' website progress using varying types of technologies. Formative assessment in the form of informal feedback conversations, praise, and constructive criticisms frequently occurred on multiple technology platforms, such as on the Twitter microblogging platform, Blackboard learning management system, as well as email announcements and asynchronous communication. Instructors provided immediate feedback through these technologies once issues and questions were spotted. When pre-service teachers reached the final stage in which the final website was turned it electronically, instructors gave grades and comments using the pre-designed rubrics as the final round of summative assessment. Our survey responses and blogs data revealed that the pre-service teachers benefited tremendously from the both instructor-provided feedback and the peer review activity.

Authentic activities create polished products valuable in their own right rather than as preparation for something else. The pre-service teachers were informed at the beginning of the class and then continually reminded that their assignment had to be a piece of polished work for their prospective job seeking purposes. Competency in using the prescribed technologies and evaluation of participant choices would serve as the assessment, as well as the completed online learning website. Their final work had to be submitted in an electronic portfolio system and evaluated by external evaluators. This would assure that real-world examples of technology integration in educational content could be presented to potential employers, thus serving as a testament of the pre-service teachers' technical abilities. As one participant noted in the survey, "I really enjoyed this assignment. I thought it was helpful for me to see how much hard work and planning it takes to put together lesson plans." Another participant commented that the assignment aligned extremely well with a real life situation and he could see himself using the website he created for a future class. 
Authentic activities allow competing solutions and diversity of outcome. The assignment promoted learning outcomes from both cognitive and affective learning dimensions. From cognitive learning perspective, the project provided ample opportunities for the pre-service teachers to comprehend the notion of online teaching, apply different learning theories and models into designing the online learning website, practice the skills of using various educational technologies, and evaluate their peer projects' from different angles. The pre-service teachers' metacognitive learning was also enhanced through continuous reflection using blogs, wikis, and the summative peer review. Participants' affective learning outcomes expected from the authentic activities include an increased motivation and appreciation of online teaching as a newly-emerging teaching method. When participants were asked "Did learning to build an eLearning support site make you more comfortable with the possibility of teaching online in the future?" 30 out of 38 expressed a positive response.

\section{RQ 2: What Were the Pre-Service Teachers' Perceptions of Their Learning Experiences?}

Overall, the pre-service teachers' responses to the survey revealed their positive learning experience during these authentic activities in this assignment as most participants agreed that this experience increased their comfort level in creating an online learning environment with authentic tasks for a K12 audience or other group setting. From the surveys and blogs this section articulates the themes that were revealed from analysing the post class surveys and blogs.

Real-life relevance. Real-life relevance emerged as a key theme when the pre-service teachers were asked about the perceived merits and drawbacks of this project. The project scenario was strategically posed to evoke a meaningful activity that simulates a potential real-life situation of which each would have to provide a remedy. When asked about their feelings toward the project scenario and how well it aligned to a real-world situation in a K-12 setting, the general consensus was positive. For example, one pre-service teacher commented on the future value in saying "I thought the real-life scenario was really helpful because it made the assignment more practical and made me want to invest more in the project because I could see how I may be in a similar situation at some point in the future."

Constructive learning. The pre-service teacher responses to the question "What did you like most about building the online learning content?" revealed that they favoured the constructive learning opportunities supported by the authentic learning activities. About half of the participants commented that they enjoyed being able to construct their own website that represented their own knowledge and skill construction. As one participant explained, "I liked the aspect of constructing your own material and lesson plan all online rather than just in person." Another noted "I always enjoyed adding content and coming up with ways to incorporate things into the website. The authentic learning project, building an online learning website, enabled us to engage in a fun, active, social process that involves deep levels of constructive learning." Participants also acknowledged that because they were given full control of the design process, they were more motivated and autonomous in creating the website. As one participant commented, "I was able to create the site the way that I wanted to and had imagined the website layout to look like. I had full control, and to be honest, it was fun making your own website." 
Collaborative learning. Collaborative learning was mainly enhanced through the peer reviewing activities. Overall, participants perceived a high value of feedback received from their peers. Peer feedback not only contained useful suggestions to improve the content materials of their websites, but also concerned the visual design and multimedia integration. In the open-ended questions, five did point out the feedback they received was rather superficial. As participants stated, "there were really not many suggestions for improvement." Table 2 show the participant ratings on how they perceived feedback from their peers.

Table 2

Participant Ratings on Perceptions of Feedback Received From the Peer Review Activity

\begin{tabular}{lll}
\hline \multicolumn{1}{c}{ Items } & Mean & SD \\
\hline $\begin{array}{l}\text { 1. The feedback from my peer reviewers helped me to improve } \\
\text { the content materials of my site. }\end{array}$ & 3.81 & 0.66 \\
$\begin{array}{l}\text { 2. The feedback from my peer reviewers helped me to improve } \\
\text { the visual design of my site. }\end{array}$ & 3.78 & 0.67 \\
$\begin{array}{l}\text { 3. The feedback from my peer reviewers helped me to improve } \\
\text { multimedia integration of my site. }\end{array}$ & 3.78 & 0.79 \\
$\begin{array}{l}\text { 4. In the peer review activity, my peer reviewers used } \\
\text { supportive languages. }\end{array}$ & 4.19 & 0.57 \\
$\begin{array}{l}\text { 5. In the peer review activity, my peer reviewers provided } \\
\text { constructive feedback. }\end{array}$ & 4.22 & 0.63 \\
$\begin{array}{l}\text { 6. In the peer review activity, my peer reviewers provided me } \\
\text { useful suggestions. }\end{array}$ & 4.19 & 0.62 \\
\hline
\end{tabular}

1 = strongly disagree; 2 =disagree; $3=$ neutral; 4 = agree; 5 = strongly agree

Use of technology. The pre-service teachers also reported that the technologies used in this project helped to enhance their technical competencies, while improving upon methods to create educational content in the future. One participant stated, "I really enjoyed learning how to create a website and add content that fits into how I would like to teach English one day." In addition, one of the respondents shared his enthusiasm for learning a new web development tool by stating, "I think that it was a good learning experience and when I was finished I felt really accomplished. I think I will try to incorporate this tool in the future." It appears that the participants were not just learning how to use technology applications, but how to use the authentic ways to build pedagogically sound activities through learning technologies.

Perceptions of online teaching. When pre-service teachers were asked about their future online teaching possibilities, there remained a favourable response for the likelihood of developing an online learning website in the future (Mean=3.78; $\mathrm{SD}=.97$ ) and even suggesting an online support environment to a friend or colleague (Mean=3.76; $\mathrm{SD}=.98$ ). Responses from open-ended questions also support this result. A majority of participants noted their awareness of future online teaching possibilities and their newly developed competencies of building an educational support site, advanced through this assignment. For example, one participant commented, "I am not the most tech savvy person so the thought of teaching online used to scare me. However, now that I know how to do 
so much more and feel much more confident in my abilities, I would be willing to teach online without hesitation."

Other participants still preferred face-to-face classes as one participant responded, "I think it made me more comfortable in terms of using the online programs, but I wouldn't consider using it because I feel it takes away from the crucial element of face-to-face human interaction." The inclusion of the online learning component enriched the learning experience, thus bringing forth an awareness of a potential future possibility with creating online content and teaching online. However, to reach preservice teachers' maximal comfort level and competence of online teaching, much professional training and development is needed along the way.

\section{RQ 3: How did Technology Facilitate the Authentic Learning Process?}

Selective combinations of web-based technologies were used to both facilitate and enhance the authentic learning process for the pre-service teachers. The researchers' goal of aligning the proper technology to the instructional design was critical. Blackboard was used for course management, but several Web 2.0 applications were leveraged to enhance collaboration and instructor and participant feedback.

A class wiki page was developed using Wikispaces, a website that allows a community of developers to contribute and edit content. For this project, it provided a platform that afforded multiple participants the opportunity to present their site in an open format for classmates to review and comment on. Additionally, each participant was required to journal their activities in a weekly blog, of which could be viewed by everyone, including people outside of the course. During this project, WordPress, a free online blogging application, was used as the platform for publishing the blog. In doing such, each participant was able to discuss their difficulties during the creation of the website and other tasks, as well as their triumphs when overcoming each challenge.

Technologies were also used extensively for providing peer feedback on the online learning websites. Table 3 presents the pre-service teacher's responses to the peer reviewer's comments and supplemental technologies used for their feedback. It was found that the comments and suggestions provided through support of these digital technologies were useful and assisted with the improvement and completion of the project. The pre-service teachers reported that they were highly engaged in the process of providing and receiving feedback owing to the technology integration.

Table 3

The Pre-Service Teachers' Ratings of the Technology Integration in the Peer Review Activity

\begin{tabular}{lll}
\hline \multicolumn{1}{c}{ Questions } & Mean & SD \\
\hline $\begin{array}{l}\text { 1. The technologies used in the peer review activity made me } \\
\text { concentrate on the review task. }\end{array}$ & 3.89 & 0.74 \\
$\begin{array}{l}\text { 2. The technologies used in the peer review activity engaged } \\
\text { me in the process of providing and receiving feedback. }\end{array}$ & 4.08 & 0.80 \\
$\begin{array}{l}\text { 3. The technologies used in the peer review activity made the } \\
\text { task fun and enjoyable. }\end{array}$ & 3.84 & 0.90 \\
\hline $\begin{array}{l}1=\text { strongly disagree; } 2 \text { =disagree; } 3=\text { neutral; } 4 \text { = agree; } 5 \text { = strongly agree } \\
\end{array}$
\end{tabular}




\section{Discussion}

The analyses of participant responses to their experiences in developing an online learning site, in concurrence with integrating Web 2.0 technology for collaboration and feedback yielded evidence that meaningful authentic learning activities are beneficial in the context of pre-service teacher training. Prior to the course project, participants were knowledgeable of the benefits afforded to K-12 education through online learning, but were deficient in using Web development tools and other collaboration technologies for the purpose of teaching and learning. Incorporating Weebly into the authentic learning experience augmented the pre-service teachers' ability to plan and implement a real-world online learning environment, which could also be used to supplement a face-to-face course. Empowering pre-service teachers' to be creative in choosing learning resources for their online learning site and not restricting their choices to venture outside of instructor requirements added further bearing to the essence of authentic learning principles posed by Herrington et al. (2003).

Web 2.o technologies were used for peer collaboration and feedback as part of the activities. The use of a personal blog, Wikispace, and Voicethread activities, were perceived as useful and supportive components for receiving feedback on the site progress. However, some participants did feel as though their peer comments lacked the critical feedback necessary to compel them to make significant changes to their site. In these instances, the peer comments were not detailed enough, or they were unsure of what was actually being critiqued on their project. Designing a peer assessment activity with broader review objectives may assist participants in giving the appropriate level of feedback within the needed areas. There may also be a need for the instructor to allocate more time in assuring that feedback tools are used in a proper manner, which concurs with prior studies emphasizing the importance of instructional guidance in Web 2.0-supported learning (Holotescu \& Grosseck, 2009; Luo \& Gao, 2012). Another challenge perceived by the pre-service teachers included balancing the amount of content they would place on the online learning site. While the instructor's goal was to give them freedom in creating and adding a variety of educational content to their website with minimal restrictions, some participants concluded that the nominal requirements felt overwhelming to manage and too time consuming. These inferences may have been due to the pre-service teacher's dearth of experience in developing curriculum at the time. The course section did consist of varying academic levels. Categorizing course participants by academic level, or even commingling teams with an advanced level participant acting as group mentor, may help with balancing out the development of relevant learning activities that would be suitable for a K-12 audience.

The instructor's intent to build an awareness of web building and digital collaboration tools, as well as expose pre-service teachers to the potential of online learning support in K-12 environments was accomplished through authentic learning activities. By aligning the instructional design to the 10 characteristics of authentic learning, the participants benefited from a meaningful experience that could be directly transferred to professional practice within a classroom or virtual learning environment. Reviewing the participant blog entries and post-survey feedback allowed the instructors to recognize the passion and comfort for digital environments some participants gained during and after the project. Though there were no definitive decisions to use online learning as their primary method for teaching and learning in the future, the project was effective in presenting it as an alternative and an augmentation to their technology skills. Future projects could place more emphasis on exposing pre-service teachers to learning management systems and digital online collaboration 
tools in which they will recognize the potential of using technology within the capacity of an online educator.

\section{Conclusion}

This study examined the design and evaluation of authentic learning activities in a teacher education learning context. The instructional activities were designed to include authentic learning activities that would provide meaningful experiences for pre-service teachers to convey into professional practice, following Herrington et al.'s (2003) 10 authentic learning characteristics.

Using a design-based research methodology, an online course was designed and the findings explain how that course aligns to Herrington et al.'s (2003) 10 authentic learning characteristics. The findings show that the pre-service teachers perceived the online learning authentic learning activities to be a good introduction to learning how to structure an online learning site, a technical skill in which they would consider using in the future. Their post-activity responses also presented evidence of comfort for using online web building applications as well as prospective desire for online teaching. The study also demonstrated the usefulness of Web 2.0 tools for supporting peer feedback activities and also providing constructive comments. Overall, the pre-service teachers did perceive the Web 2.0 technology supported peer and instructor feedback and that the collaboration tools were also enjoyable to use.

This study, however, is not without limitations. As the study is primarily relied on self-report data, some objective dimensions of pre-service teacher learning, such as performance, were not measured and evaluated. As the study was implemented in one particular setting, generalizations of results and implications from this study were limited. Future research in a different setting or with a disparate participant group may provide further insights on the impact of authentic learning design.

\section{References}

Amory, A. (2014). Toll-mediated authentic learning in an educational technology course: A designbased innovation. Interactive Learning Environments, 22(4), 497-513.

Archambault, L., Debruler, K., \& Friedhoff, J. R. (2014). K-12 online and blended teacher licensure: Striking a balance between policy and preparedness. Journal of Technology and Teacher Education, 22(1), 83-106.

Behizadeh, N., \& Fink, L. S. (2015). Engaging students through authentic and effective literacy instruction. Voices from the Middle, 23(1), 40-50.

Bjekic, D., Krneta, R., \& Milosevic, D. (2010). Teacher education from e-learner to e-teacher: Master curriculum. Turkish Online Journal of Educational Technology 9(1), 202-212. 
Blackwell, P. J., Futrell, M. H., \& Imig, D. G. (2003). Burnt water paradoxes of schools of education. Phi Delta Kappa, 85(5), 356-361.

Brown, J. S., Collins, A., \& Duguid, P. (1989). Situated cognition and the culture of learning. Educational Researcher, 18(1), 32-42.

Cusworth, R., \& Whiting, P. (1994). Beginning teachers' attitudes to preservice training. Paper presented at Australian Association for Research in Education Conference, Newcastle, UK.

Demiray, U. (2011). Distance education and eLearning practices: In Turkey and Eastern countries. OpenEducationEuropa . Retrieved from https://www.openeducationeuropa.eu/en/article/Distance-education-and-eLearningpractices\%3A-In-Turkey-and-Eastern-countries\#main-content

El-Ghareeb, H., \& Riad, A. (2011). Empowering adaptive lectures through activation of intelligent and web 2.o technologies. International Journal on E-Learning, 1O(4), 365-391.

Florida, R., Kaimal, G., Oblinger, D., \& Blessing. L. (2003). How generations X and Y (Millenials) will reshape higher education. Society for College and University Planning Virtual Seminar.

Gulikers, J., Bastiaens, T., \& Kirschner, P. (2004). A five-dimensional framework for authentic assessment. Educational Technology Research and Development, 52(3), 67-86.

Herrington, J., \& Oliver, R. (2000). An instructional design framework for authentic learning environments. Educational Technology Research and Development, 48(3), 23-48.

Herrington, J., Oliver, R., \& Reeves, T. C. (2003). Patterns of engagement in authentic online learning environments. Australian Journal of Educational Technology, 19(1), 59-71.

Holotescu, C. \& Grosseck, G. (2009). Using microblogging in education. Case study: Cirip.ro. Paper presented at the 6th Conference on e-Learning Applications, Cairo, Egypt.

Hossainy, F. N., Zare, H., Hormozi, M., Shaghaghi, F., \& Kaveh, M. H. (2012). Designing and implementing a situated learning program and determining its impact on the students' motivation and learning. Turkish Online Journal of Distance Education, 13(2), 36-47.

International Association for K-12 Online Learning (iNOCOL). (2013). Fast facts about online learning [PDF]. Retrieved from http://www.inacol.org/resource/fast-facts-about-online-learning/

Kennedy, K., \& Archambault, L. (2012a). Offering pre-service teachers field experiences in K-12 online learning: A national survey of teacher education programs. Journal of Teacher Education, 63(3), 185-200.

Kennedy, K., \& Archambault, L. (2012b). Design and development of field experiences in K-12 online learning environments. Journal of Applied Instructional Design, 2(1), 35-49.

Kreber, C., Klampfleitner, M., McCune, V., Bayne, S., \& Knottenbelt. (2007). What do you mean by "Authentic"? A comparative review of the literature on conceptions of authenticity in teaching. Adult Education Quarterly, 58(1), 22-43. 
Latham, G., \& Carr, N. (2012a). Authentic learning for pre-service teachers in a technology-rich environment. Journal of Learning Design, 8(3), 65-66.

Latham, G., \& Carr, N. (2012b). Building on authentic Learning for Pre-Service Teachers in a Technology-Rich Environment. Journal of Learning Design, 5(1), 32-42.

Lave, J., \& Wenger, E. (1991). Situated learning: Legitimate peripheral participation. New York: Cambridge University Press.

Liu, F., \& Cavanaugh, C. (2011). High enrolment course success factors in virtual school: Factors influencing student academic achievement. International Journal on E-Learning, 1O(4), 393418.

Luo, T., \& Gao, F. (2012). Enhancing classroom learning experience by providing structures to microblogging-based activities. Journal of Information Technology Education, 11, 199-211.

Martens, R. L., Gulikers, J., \& Bastiaens, T. (2004). The impact of intrinsic motivation on e-learning in authentic computer tasks. Journal of Computer Assisted Learning, 20(5), 368-376.

Middleton, J., Gorard, S., Taylor, C., \& Bannan-Ritland, B. (2008). The "complete "design experiment: from soup to nuts. In A.E. Kelly, R.A. Lesh, \& J.Y. Baek (Eds.), Handbook of design research methods in education: innovations in science, technology, engineering and mathematics learning and teaching (pp. 21-46). New York and Oxford: Routledge, Taylor and Francis.

Newmann, F. M., \& Wehlage, G. G. (1993). Educational leadership: Five standards of authentic instruction. Educational Leadership, 5o(7), 8-12.

Slavkin, M. L. (2004). Authentic learning: How learning about the brain can shape the development of students. Toronto: ScarecrowEducation.

Snape, P., \& Fox-Turnbull, W. (2013). Perspectives of authenticity: Implementation in technology education. International Journal of Technology and Design Education, 23(1), 51-68.

Stemler, S. (2001). An overview of content analysis. Practical Assessment, Research \& Evaluation, $7(17)$. Retrieved from http://PAREonline.net/getvn.asp?v $=7 \& n=17$

Teräs, H., Teräs, M., \& Herrington, J. (2012). A reality check: Taking authentic e-learning from design to implementation. In T. Amiel \& B. Wilson (Eds.), Proceedings of World Conference on Educational Multimedia, Hypermedia and Telecommunications, 2012 (pp. 2219-2228). Chesapeake, VA: AACE.

Turnbull, W. (2002). The place of authenticity in technology in the New Zealand curriculum. International Journal of Technology and Design Education, 12, 23-40.

Wang, F., \& Hannafin, M. J. (2005). Design-based research and technology-enhanced learning environments. Educational Technology Research and Development, 53(4), 5-23. 

Luo, Murray, and Crompton

\section{Athabasca}

University

cc) (i)

(c) 